\title{
High-spin intermediates of the photolysis of 2,4,6-triazido-3-chloro-5-fluoropyridine
}

\author{
Sergei V. Chapyshev ${ }^{*}$, Denis V. Korchagin ${ }^{1}$, Patrik Neuhaus ${ }^{2}$ \\ and Wolfram Sander ${ }^{2}$
}

\section{Full Research Paper}

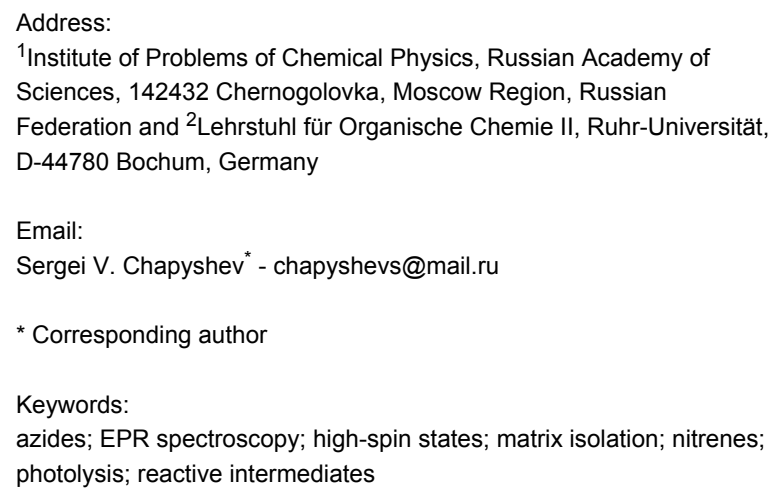

\begin{abstract}
In contrast to theoretical expectations, the photolysis of 2,4,6-triazido-3-chloro-5-fluoropyridine in argon at $5 \mathrm{~K}$ gives rise to EPR peaks of just two triplet mononitrenes, two quintet dinitrenes, and a septet trinitrene. EPR spectral simulations in combination with DFT calculations show that observable nitrenes can be assigned to triplet 2,4-diazido-3-chloro-5-fluoropyridyl-6-nitrene $\left(D_{\mathrm{T}}=1.026 \mathrm{~cm}^{-1}, E_{\mathrm{T}}=0\right)$, triplet 2,6-diazido-3-chloro-5-fluoropyridyl-4-nitrene $\left(D_{\mathrm{T}}=1.122 \mathrm{~cm}^{-1}, E_{\mathrm{T}}=0.0018 \mathrm{~cm}^{-1}\right)$, quintet 4-azido-3-chloro-5-fluoropyridyl-2,6-dinitrene $\left(D_{\mathrm{Q}}=0.215 \mathrm{~cm}^{-1}, E_{\mathrm{Q}}=0.0545 \mathrm{~cm}^{-1}\right)$, quintet 2-azido-3-chloro-5-fluoropyridyl4,6-dinitrene $\left(D_{\mathrm{Q}}=0.209 \mathrm{~cm}^{-1}, E_{\mathrm{Q}}=0.039 \mathrm{~cm}^{-1}\right)$ and septet 3-chloro-5-fluoropyridyl-2,4,6-trinitrene $\left(D_{\mathrm{S}}=-0.1021 \mathrm{~cm}^{-1}\right.$, $\left.E_{\mathrm{S}}=-0.0034 \mathrm{~cm}^{-1}\right)$. Preferential photodissociation of the azido groups located in ortho-positions to the fluorine atom of pyridines is associated with strong $\pi$-conjugation of these groups with the pyridine ring. On photoexcitation, such azido groups are more efficiently involved in reorganization of the molecular electronic system and more easily adopt geometries of the locally excited predissociation states.
\end{abstract}

\section{Introduction}

High-spin nitrenes are highly reactive intermediates formed during photolysis or thermolysis of aromatic polyazides. Both these processes are widely used in modern science and technology [1-6]. When aromatic polyazides contain nonequivalent azido groups, these groups can undergo selective photolysis, providing important information about the selective cleavage of chemical bonds in organic molecules with light. The direction and selectivity of such processes can be monitored with EPR spectroscopy allowing the reliable identification of isomeric high-spin nitrenes [7-10]. Thus, previous EPR studies have 
shown that irradiation of triazide 1a with light at $\lambda=313 \mathrm{~nm}$ selectively gave quintet dinitrene $\mathbf{4 a}$ as the major intermediate product (Scheme 1) [7,8]. Most recently, a similar selectivity was observed during the photolysis of triazide $\mathbf{1} \mathbf{b}$ where quintet dinitrene $\mathbf{4 b}$ was the major intermediate product (Scheme 1) [9] By contrast, the photolysis of triazide 7 occurs selectively on the azido group located on the $\gamma$-phenyl ring, yielding dinitrene 9 as a single quintet intermediate (Scheme 1) [10]. All these photochemical studies became possible owing to extensive EPR investigations of various high-spin nitrenes in the past two decades [11-31]. Nowadays, the EPR spectral identification of high-spin nitrenes is based on comparison of their zero-field splitting (ZFS) parameters derived from experimental EPR spectra and calculated by quantum chemistry methods. The most accurate theoretical estimations are obtained at the PBE/ DZ level of theory, which overestimates the experimental ZFS values of nitrenes by only about $10 \%$ [32]. This accuracy of calculations is sufficient for reliable identification of isomeric dinitrenes $\mathbf{4 a}-\mathbf{c}$ and $\mathbf{5 a}-\mathbf{c}$ formed during the photolysis of triazides 1a-c (Scheme 1). Although these dinitrenes show nearly the same $D_{\mathrm{Q}}$ values $\left(\approx 0.21 \mathrm{~cm}^{-1}\right)$, the $E_{\mathrm{Q}}$ values of $4 \mathbf{a}-\mathbf{c}$ and $5 \mathbf{a}-\mathbf{c}$ differ significantly $\left(E_{\mathrm{Q} 4} \approx 0.055 \mathrm{~cm}^{-1}, E_{\mathrm{Q} 5} \approx\right.$ $0.040 \mathrm{~cm}^{-1}$ ), thus allowing one to unambiguously discriminate such isomers [29-31].

A new level of complexity is the EPR identification of highspin intermediates formed during the photolysis of asymmetric triazides such as $\mathbf{1 1}$ (Scheme 2). Theoretically, the photolysis of triazide 11 may give three triplet nitrenes 12-14, three quintet dinitrenes 15-17, and septet trinitrene 18. So far, no attempt was undertaken to discriminate such structurally alike isomers as quintet dinitrenes $\mathbf{1 6}$ and $\mathbf{1 7 .}$

In the present work, we report on matrix isolation and EPR studies of high-spin intermediates formed during the photolysis of asymmetric triazide 11, providing the first information about selective photochemical decomposition of three nonequivalent azido groups in monocyclic aromatic compounds.

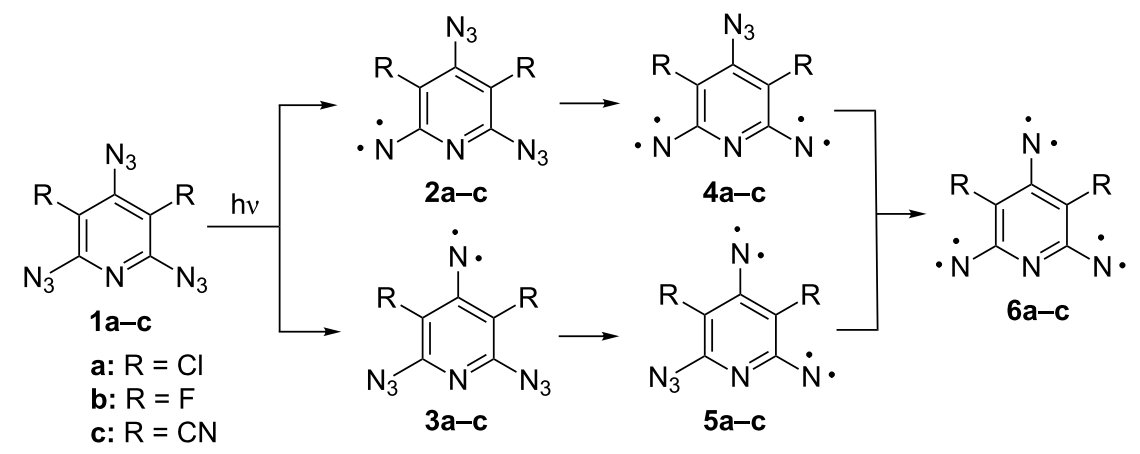<smiles>[3H]c1ccc(-c2cc(-c3ccc(N)cc3)nc(-c3ccc(N)cc3)c2)cc1</smiles><smiles>N#[N+]c1ccc(-c2cc(-c3ccc(N)cc3)nc(-c3ccc([N+]#N)cc3)c2)cc1</smiles><smiles>CNc1ccc(-c2cc(-c3ccc([N+]=[N-])cc3)nc(-c3ccc([N+]=[N-])cc3)c2)cc1</smiles> 


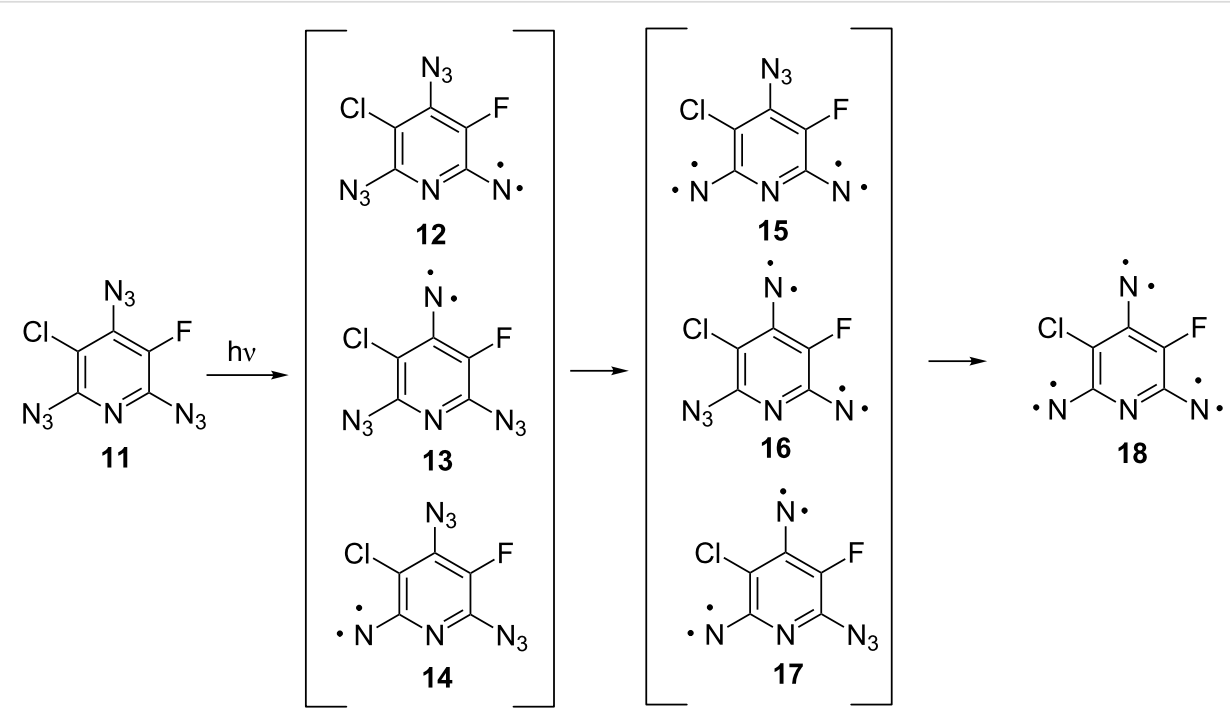

Scheme 2: Possible photoproducts of triazide 11.

\section{Results and Discussion}

Brief UV irradiation ( $2 \mathrm{~min}, \lambda=260-320 \mathrm{~nm}$ ) of triazide 11 in the argon matrix leads to the appearance of just two strong EPR signals of triplet nitrenes at 6985 and $7217 \mathrm{G}$ as well as weak $Y_{2}$-transitions of quintet dinitrenes at 3077 and $3337 \mathrm{G}$. Upon more extended irradiation, new signals in the 30-7000 $\mathrm{G}$ region appear due to gradual accumulation of high-spin nitrenes. The intensities of these signals reached their maximum values after 45 min of irradiation and then gradually decayed upon further irradiation. The EPR spectrum recorded after 45 min of irradiation is shown in Figure 1b.

The EPR spectral simulations show that the products of the reaction are two triplet nitrenes with $D_{\mathrm{T}}=1.026 \mathrm{~cm}^{-1}, E_{\mathrm{T}}=$ $0 \mathrm{~cm}^{-1}$ and $D_{\mathrm{T}}=1.122 \mathrm{~cm}^{-1}, E_{\mathrm{T}}=0.0018 \mathrm{~cm}^{-1}$, two quintet dinitrenes with $D_{\mathrm{Q}}=0.209 \mathrm{~cm}^{-1}, E_{\mathrm{Q}}=0.039 \mathrm{~cm}^{-1}$ and $D_{\mathrm{Q}}=$ $0.215 \mathrm{~cm}^{-1}, E_{\mathrm{Q}}=0.0545 \mathrm{~cm}^{-1}$, and a septet trinitrene with $D_{\mathrm{S}}=-0.1021 \mathrm{~cm}^{-1}, E_{\mathrm{S}}=-0.0034 \mathrm{~cm}^{-1}$ in a 14:12:20:5:1 ratio (Figure 1a). Surprisingly, the ZFS parameters of quintet and septet nitrenes formed in the reaction were very close to the magnetic parameters of previously studied quintet dinitrenes $4 \mathbf{c}$ $\left(D_{\mathrm{Q}}=0.210 \mathrm{~cm}^{-1}, E_{\mathrm{Q}}=0.039 \mathrm{~cm}^{-1}\right)$ and $5 \mathbf{c}\left(D_{\mathrm{Q}}=0.209 \mathrm{~cm}^{-1}\right.$, $\left.E_{\mathrm{Q}}=0.0542 \mathrm{~cm}^{-1}\right)$ and septet trinitrene $6 \mathbf{c}\left(D_{\mathrm{S}}=-0.1011 \mathrm{~cm}^{-1}\right.$, $E_{\mathrm{S}}=-0.0043 \mathrm{~cm}^{-1}$ ) [31]. The EPR spectra of such nitrenes, including the complete assignment of all transitions, have been reported previously [29-31]. Quintet and septet nitrenes formed during the photolysis of triazide $\mathbf{1 1}$ display very similar EPR spectra.

The septet product formed in the reaction can be safely assigned to trinitrene 18 since only this trinitrene has a septet spin state. According to EPR spectral simulations (Figure 1a), this trini-

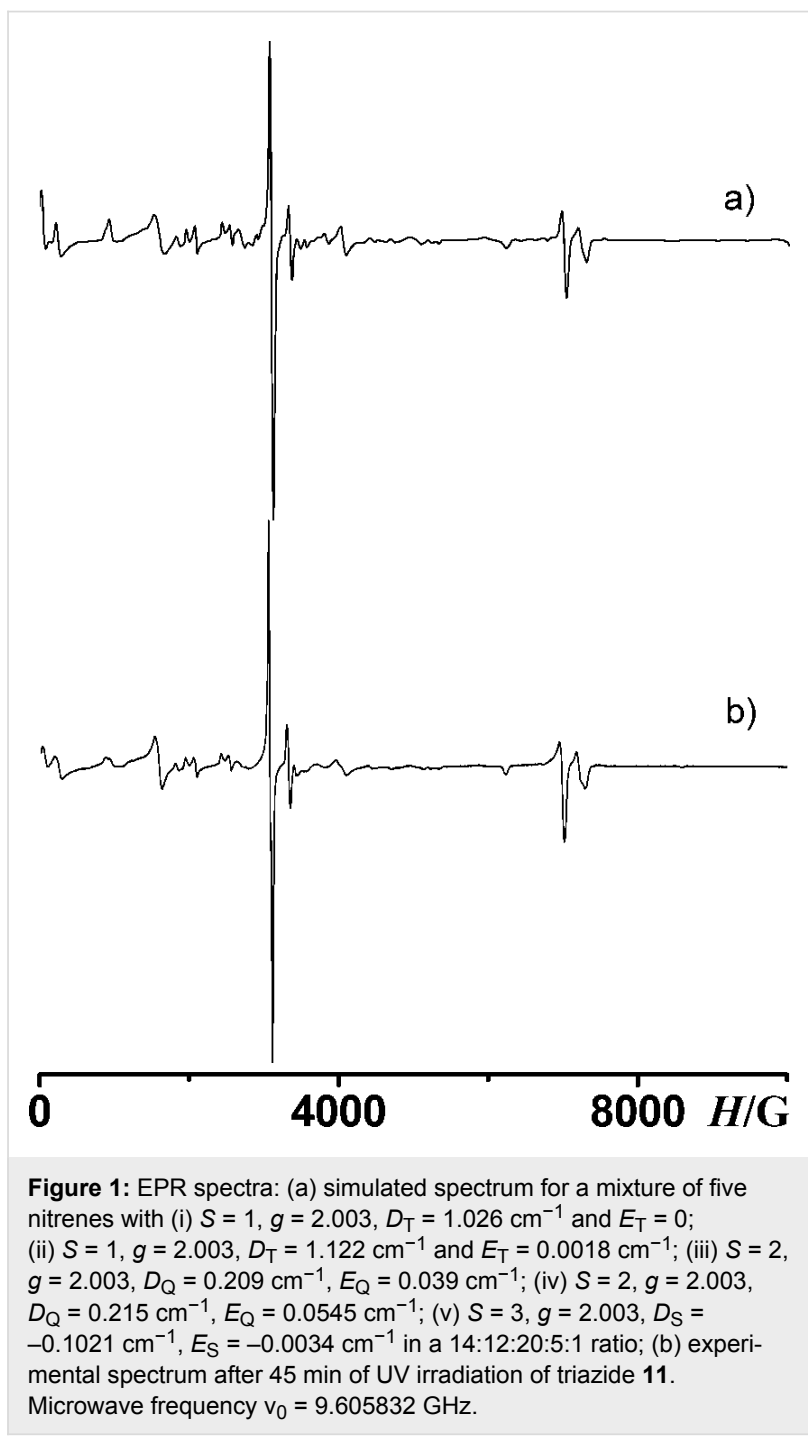


trene is formed in ca. $2 \%$ yield. Due to different substituents in positions 3 and 5 of the pyridine ring, trinitrene 18 has different angles $\Theta_{1}, \Theta_{2}, \Theta_{3}$ between the nitrene $\mathrm{C}-\mathrm{N}$ bonds and different Mulliken spin populations on the nitrene units (Table 1). Theoretically, such asymmetric trinitrenes should show rather large $E_{\mathrm{S}}$ values [30]. Nevertheless, the $E_{\mathrm{S}}$ value of trinitrene 18 is even smaller than that of $C_{2 v}$ symmetric trinitrene $6 \mathbf{c}$ [31]. DFT calculations show that trinitrene 18, on comparison with $C_{2 v}$ symmetric trinitrenes $\mathbf{6 a - c}$, has slightly different orientations of the principal magnetic axes due to the presence of only one heavy chlorine atom. Thus, the principal axes $\boldsymbol{D}_{X X} \mathbf{S S}$ and $\boldsymbol{D}_{\boldsymbol{X} \boldsymbol{X}}{ }^{\text {Tot }}$ of $C_{2 v}$ symmetric trinitrene $\mathbf{6 a}$ were directed along the line connecting the nitrene units in positions 2 and 6 of the pyridine ring and were parallel to the $\boldsymbol{D}_{\boldsymbol{Z} Z} \mathbf{S O}$ axis of the spin-orbit tensor $\boldsymbol{D}^{\mathbf{S O}}$ connecting two heavy chlorine atoms in positions 3 and 5 of the pyridine ring [30]. In the case of trinitrene 18, the $D_{Z Z} \boldsymbol{S O}^{\mathbf{S O}}$ axis of the spin-orbit tensor $\boldsymbol{D}^{\mathbf{S O}}$ almost coincides with the $\mathrm{C}(3)-\mathrm{Cl}$ bond (Figure 2). As a result, the principal axis $D_{X X}{ }^{\text {Tot }}$ in trinitrene 18 is turned away from the line connecting the $\alpha$-nitrene units by about $4^{\circ}$.
Previous studies of nitrenes $\mathbf{6 a}-\mathbf{c}$ have shown that the most accurate theoretical evaluations of $D_{\mathrm{S}}$ and $E_{\mathrm{S}}$ by the DFT approach were obtained by using the PBE and BLYP functionals in combination with the DZ or EPRII basis sets [32]. Extensive DFT calculations performed in the present work show that the best agreement between the experiment and theory is observed at the BLYP/EPRII level of theory, overestimating the experimental $D_{\mathrm{S}}$ and $E_{\mathrm{S}}$ values of trinitrene 18 by only $6 \%$ (Table 2 ). The breakdown of $D_{\mathrm{S}}$ and $E_{\mathrm{S}}$ into $D^{\mathrm{SS}}, D^{\mathrm{SO}}, E^{\mathrm{SS}}$, and $E^{\mathrm{SO}}$ reveals that the BLYP/EPRII calculations are especially good in estimations of the spin-orbit coupling contributions $E^{\mathrm{SO}}$ to the small parameters $E_{\mathrm{S}}$ of septet trinitrenes (Table 3).

By analogy with previous studies of dinitrenes 5a-c [29-31], the quintet molecule with $D_{\mathrm{Q}}=0.215 \mathrm{~cm}^{-1}$ and $E_{\mathrm{Q}}=0.0545 \mathrm{~cm}^{-1}$ can safely be assigned to dinitrene 15 with $\Theta=115.7^{\circ}$. Thus, for instance, quintet dinitrene 5a showed $D_{\mathrm{Q}}=0.202 \mathrm{~cm}^{-1}$ and $E_{\mathrm{Q}}=0.0554 \mathrm{~cm}^{-1}$ [30], and its difluoro-derivative $\mathbf{5 b}$ displayed $D_{\mathrm{Q}}=0.213 \mathrm{~cm}^{-1}$ and $E_{\mathrm{Q}}=0.0556 \mathrm{~cm}^{-1}$ [29]. The most accurate theoretical estimations of the magnetic parameters in dini-

Table 1: Mulliken spin populations $\rho_{\mathrm{N}}$ on the nitrene units and dipolar angles $\Theta$ between the nitrene $\mathrm{C}-\mathrm{N} / \mathrm{C}-\mathrm{N}$ bonds in high-spin nitrenes $\mathbf{1 5 - 1 8}$.

Parameter

15

\begin{tabular}{ll}
\hline$\rho_{\mathrm{N}}$ & $1.63(2 \mathrm{~N})$ \\
& $1.62(6 \mathrm{~N})$
\end{tabular}

$\Theta\left[{ }^{\circ}\right]$
$115.7(2 \mathrm{~N} / 6 \mathrm{~N})$
Nitrene

16

$1.55(4 \mathrm{~N})$
$1.53(6 \mathrm{~N})$

$121.6(4 N / 6 N)$
17

$1.53(2 \mathrm{~N})$
$1.55(4 \mathrm{~N})$

$125.4(2 \mathrm{~N} / 4 \mathrm{~N})$
18

$1.62(2 \mathrm{~N})$
$1.54(4 \mathrm{~N})$

$1.63(6 \mathrm{~N})$

$124.8(2 \mathrm{~N} / 4 \mathrm{~N})$

$121.2(4 \mathrm{~N} / 6 \mathrm{~N})$

$113.9(2 \mathrm{~N} / 6 \mathrm{~N})$

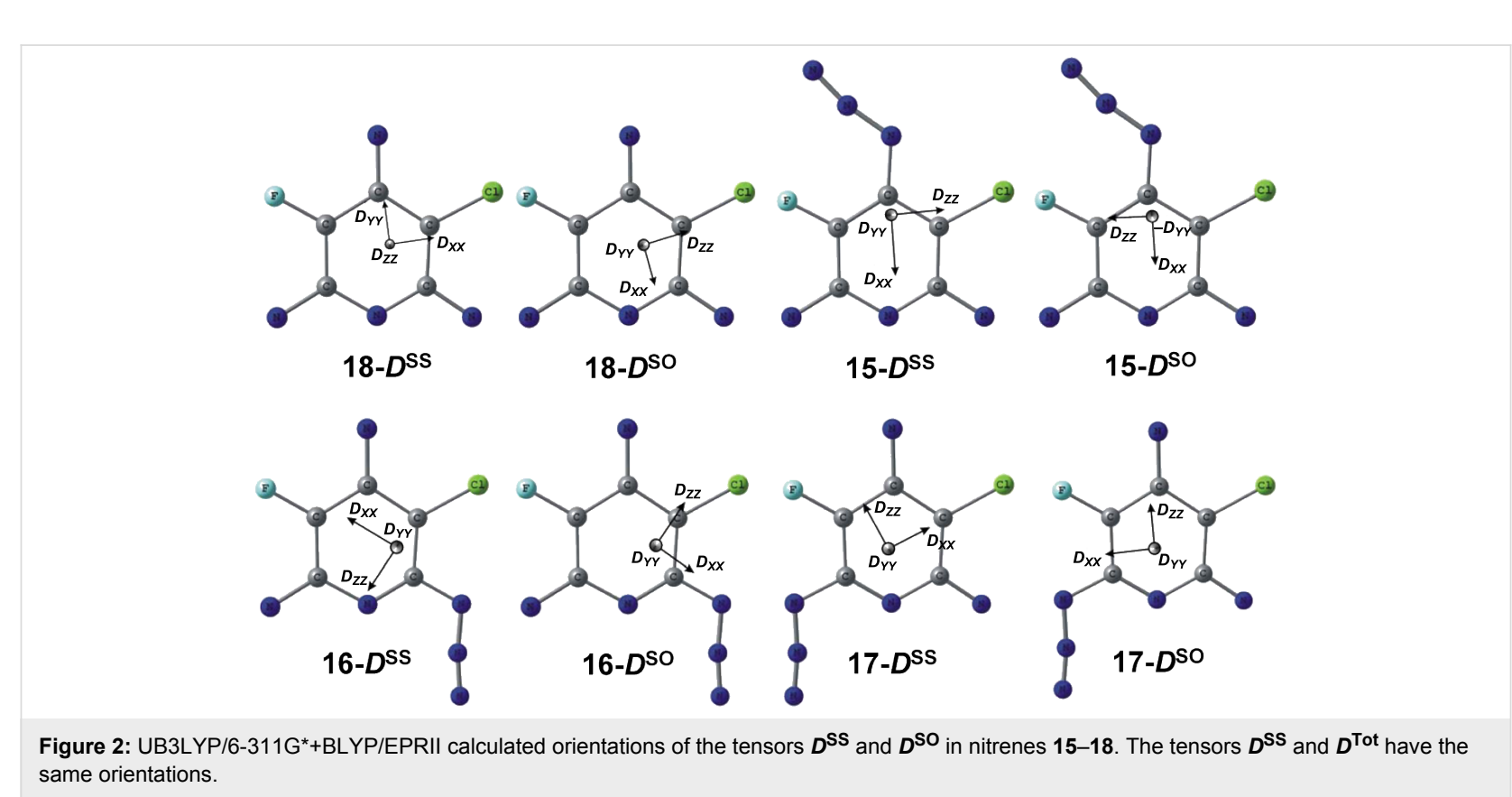




\begin{tabular}{|c|c|c|c|c|}
\hline Method & $D / E$ of 15 & $D / E$ of 16 & $D / E$ of 17 & $D / E$ of $\mathbf{1 8}$ \\
\hline $\mathrm{PBE} / \mathrm{TZV}$ & - & - & - & $-0.1122 /-0.0044$ \\
\hline $\mathrm{PBE} / 6-311+\mathrm{G}^{*}$ & - & - & - & $-0.1104 /-0.0044$ \\
\hline BLYP/DZ & $0.2249 / 0.0610$ & $0.2302 / 0.0398$ & $0.2304 / 0.0422$ & $-0.1116 /-0.0045$ \\
\hline PBE/DZ & $0.2226 / 0.0609$ & $0.2279 / 0.0400$ & $0.2303 / 0.0416$ & $-0.1108 /-0.0046$ \\
\hline PBE/EPRII & $0.2261 / 0.0574$ & $0.2265 / 0.0369$ & $0.2289 / 0.0387$ & $-0.1089 /-0.0042$ \\
\hline BLYP/EPRII & $0.2259 / 0.0572$ & $0.2270 / 0.0366$ & $0.2269 / 0.0394$ & $-0.1090 /-0.0036$ \\
\hline Experiment & $0.2150 / 0.0545$ & $0.2090 / 0.0390$ & - & $-0.1021 /-0.0034$ \\
\hline
\end{tabular}

\begin{tabular}{|c|c|c|c|}
\hline Nitrene & Method & $D^{S S} / E^{S S}$ & $D^{\mathrm{SO}} / E^{\mathrm{SO}}$ \\
\hline \multirow[t]{3}{*}{15} & PBE/DZ & $0.201 / 0.059$ & $0.021 / 0.002$ \\
\hline & PBE/EPRII & $0.204 / 0.055$ & $0.022 / 0.002$ \\
\hline & BLYP/EPRII & $0.202 / 0.055$ & $0.024 / 0.002$ \\
\hline \multirow[t]{3}{*}{16} & PBE/DZ & $0.212 / 0.040$ & $0.016 / 0.001$ \\
\hline & PBE/EPRII & $0.211 / 0.036$ & $0.016 / 0.001$ \\
\hline & BLYP/EPRII & $0.209 / 0.035$ & $0.018 / 0.001$ \\
\hline \multirow[t]{3}{*}{17} & $\mathrm{PBE} / \mathrm{DZ}$ & $0.229 / 0.034$ & $0.002 / 0.007$ \\
\hline & PBE/EPRII & $0.227 / 0.031$ & $0.002 / 0.007$ \\
\hline & BLYP/EPRII & $0.226 / 0.030$ & $0.002 / 0.007$ \\
\hline \multirow[t]{3}{*}{18} & $\mathrm{PBE} / \mathrm{DZ}$ & $-0.1031 /-0.0078$ & $-0.008 / 0.003$ \\
\hline & PBE/EPRII & $-0.1007 /-0.0074$ & $-0.008 / 0.003$ \\
\hline & BLYP/EPRII & $-0.0996 /-0.0075$ & $-0.009 / 0.004$ \\
\hline
\end{tabular}

trene 5a-c were obtained by using the $\mathrm{PBE} / \mathrm{DZ}$ calculations [32]. Such calculations are also the most accurate for estimations of $D_{\mathrm{Q}}$ in dinitrene 15 (Table 2). The theoretical value of $D_{\mathrm{Q}}=0.2226 \mathrm{~cm}^{-1}$ obtained from the PBE/DZ calculations overestimates the experimental $D_{\mathrm{Q}}$ value in dinitrene 15 by just $3.5 \%$. On the other hand, as in the case with trinitrene $\mathbf{1 8}$, the BLYP/EPRII calculations predict the most realistic value of $E_{\mathrm{Q}}=0.0572 \mathrm{~cm}^{-1}$ in dinitrene 15 (Table 2). According to EPR spectral simulations, dinitrene $\mathbf{1 5}$ is formed in the photolysis of triazide $\mathbf{1 1}$ in only ca. $10 \%$ yield.

The major quintet product of the reaction is the dinitrene with $D_{\mathrm{Q}}=0.209 \mathrm{~cm}^{-1}$ and $E_{\mathrm{Q}}=0.039 \mathrm{~cm}^{-1}(38 \%)$. This dinitrene can be assigned either to dinitrene $\mathbf{1 6}$ or to dinitrene $\mathbf{1 7}$ Previous EPR studies have shown that quintet dinitrenes with $\Theta=121 \pm 1^{\circ}$ displayed $E_{\mathrm{Q}}=0.04 \pm 0.001 \mathrm{~cm}^{-1}$, and dinitrenes with $\Theta=125 \pm 1^{\circ}$ showed $E_{\mathrm{Q}}=0.035 \pm 0.001 \mathrm{~cm}^{-1}$ [21,29-31]. According to DFT calculations, the dipolar angles $\Theta$ in dinitrenes $\mathbf{1 6}$ and $\mathbf{1 7}$ are equal to $121.6^{\circ}$ and $125.4^{\circ}$, respectively (Table 1). These data suggest that the dinitrene with $E_{\mathrm{Q}}=$ $0.039 \mathrm{~cm}^{-1}$ can safely be assigned to dinitrene 16 . The most realistic theoretical estimation of $E_{\mathrm{Q}}$ in dinitrene $\mathbf{1 6}$ is obtained from $\mathrm{PBE} / \mathrm{DZ}$ calculations of the spin-spin interaction parameter $E_{Q}$ SS (Table 3). This fact indicates that the contribution of the spin-orbit interactions to the total parameter $E_{\mathrm{Q}}$ of dinitrene $\mathbf{1 6}$ is quite small, as is typical for most of quintet dinitrenes [32].

Although we do not observe diagnostic signals of dinitrene 17 in the experimental EPR spectrum, this dinitrene may be a minor product of the photolysis of triazide 11. Extensive EPR spectral simulations show that five other quintet molecules with $E_{\mathrm{Q}} / D_{\mathrm{Q}}=0.038 / 0.213,0.037 / 0.217,0.036 / 0.221,0.035 / 0.225$ and $0.034 / 0.229$ also display intense $Y_{2}$ transitions at $3077 \mathrm{G}$ beside dinitrene 16 with $E_{\mathrm{Q}} / D_{\mathrm{Q}}=0.039 / 0.209$. In EPR spectra of individual molecules, these six quintet species are easily identified owing to different positions of their $Z_{1}, X_{1}, X_{2}, Z_{2}, A_{1}$ and $A_{2}$ transitions (See Supporting Information File 1). However, when the mixture of dinitrenes $\mathbf{1 6}$ and $\mathbf{1 7}$ is formed, isomer 17 becomes detectable in EPR spectra only at relatively high concentrations $(>5 \%)$. Thus, for instance, in EPR spectra of two quintet molecules with $E_{\mathrm{Q}} / D_{\mathrm{Q}}=0.039 / 0.209$ and $0.038 /$ 0.213 , the minor component with $E_{\mathrm{Q}} / D_{\mathrm{Q}}=0.038 / 0.213$ becomes visible when its ratio to the major component exceeds 
1:6 (14\%). Based on these data, we do not exclude that dinitrene 17 with $E_{\mathrm{Q}} / D_{\mathrm{Q}} \approx 0.036 / 0.221$ may be formed in ca. $5 \%$ yield along with dinitrene $16(\approx 33 \%)$ during the photolysis of triazide $\mathbf{1 1}$.

Theoretically, several triplet mononitrenes can be formed during the photolysis of triazide 11 (Figure 3). As a rule, triplet pyridyl-2-nitrenes show $D_{\mathrm{T}}=1.03 \pm 0.02 \mathrm{~cm}^{-1}$ and $E_{\mathrm{T}} \approx$ $0 \mathrm{~cm}^{-1}$, while triplet pyridyl-4-nitrenes show $D_{\mathrm{T}}=1.13 \pm$ $0.02 \mathrm{~cm}^{-1}$ and $E_{\mathrm{T}} \approx 0 \mathrm{~cm}^{-1}$ [29-31]. When chlorine atoms are set in ortho-positions to the nitrene center, such triplet pyridylnitrenes show $E_{\mathrm{T}}>0.003 \mathrm{~cm}^{-1}$ [30]. Since one of triplet mononitrenes obtained in the present work shows $D_{\mathrm{T}}=$ $1.026 \mathrm{~cm}^{-1}$ and $E_{\mathrm{T}}=0 \mathrm{~cm}^{-1}$, this nitrene can safely be assigned to 12 (Scheme 2). Another triplet mononitrene shows a $D_{\mathrm{T}}=$ $1.122 \mathrm{~cm}^{-1}$ typical for pyridyl-4-nitrenes and a small parameter $E_{\mathrm{T}}=0.0018 \mathrm{~cm}^{-1}$ that is characteristic for triplet nitrenes with one chlorine atom in an ortho-position to the nitrene center. This mononitrene can safely be assigned to 13. According to EPR spectral simulations, triplet nitrenes $\mathbf{1 2}$ and $\mathbf{1 3}$ are formed in 27 and $23 \%$ yield, respectively. DFT calculations of the parameters $D_{\mathrm{T}}$ SS agree well with the experiment, overestimating the $D_{\mathrm{T}}$ parameters of nitrenes $\mathbf{1 2}$ and $\mathbf{1 3}$ by just 2 and 3\%, respectively (Figure 3). Unfortunately, as in the case of many other triplet mononitrenes [32], such calculations are too crude for estimations of the parameters $E_{\mathrm{T}}$, predicting $E_{\mathrm{T}}=0.006 \pm$ $0.001 \mathrm{~cm}^{-1}$ for all isomers of $\mathbf{1 2 - 1 4}$.

Recent EPR studies have shown that the best EPR spectral simulations for high-spin nitrenes were obtained only when an additional line-broadening parameter $\Gamma(E)$ was used in the spinHamiltonian calculations [24]. The necessity of the use of this parameter in calculations is due to the presence in matrices of numerous conformational isomers of the starting azides. Upon UV irradiation, these conformers decompose to high-spin nitrenes that slightly differ each from other in the angles $\mathrm{N}-\mathrm{C}-\mathrm{C}$ and $\Theta$ and the parameters $E$. The formation of such high-spin nitrenes affects significantly the line-width and inten- sity of some lines in the experimental EPR spectra. Similar effects were also observed in EPR spectra of nitrenes 15-18. In order to adequately reproduce the experimental EPR spectrum from Figure 1b, the line-broadening parameters $\Gamma(E)=75 \mathrm{MHz}$ for dinitrenes 15 and 16 and $\Gamma(E)=40 \mathrm{MHz}$ for trinitrene 18 were used in the spectral simulations. According to these values of $\Gamma(E)$, the variations in the angles $\Theta$ for dinitrenes $\mathbf{1 5 / 1 6}$ and trinitrene 18 do not exceed $0.7^{\circ}$ and $0.4^{\circ}$, respectively. Despite these very small variations in the angles $\Theta$, all our attempts to theoretically reproduce the experimental EPR spectrum from Figure $1 \mathrm{~b}$ without the use of the line-broadening parameters $\Gamma(E)$ were unsuccessful. EPR spectra of nitrenes 15, 16 and 18 simulated for $\Gamma(E)=0,40$ and $75 \mathrm{MHz}$ are presented in Supporting Information File 1.

The results obtained show that almost all triplet and quintet nitrenes detected in the present study arise from the photolysis of the azido groups located in ortho-positions to the fluorine atom of pyridines. On comparison with the chlorine, the fluorine is a much more electron-negative and less bulky atom. Both of these factors favor strong $\pi$ - conjugation of the orthoazido groups with the pyridine ring. On photoexcitation, such azido groups should be more efficiently involved in reorganization of the molecular electronic system and more easily adopt geometries of the locally excited predissociation states [33,34]. DFT calculations show that namely azido groups located in positions 4 and 6 of triazide $\mathbf{1 1}$ have high localization of the lowest unoccupied molecular orbital (LUMO) density (see below in Figure 4). Similar localization of the LUMO density has previously been calculated for the azido group set on the $\gamma$-phenyl ring of triazide 7 , which underwent selective photolysis to form triplet nitrene 8 (Scheme 1) [10]. All these data indicate that of the three azido groups of triazide $\mathbf{1 1}$ the azido groups in ortho-positions to the fluorine atom should be the most photoactive.

The photodissociation of the azido groups in triazide $\mathbf{1 1}$ can be modeled by computational methods $[8,34]$. Thus, for instance,

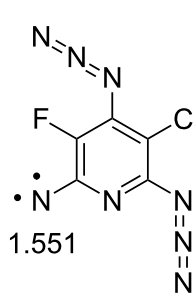

12<smiles></smiles>

13-syn

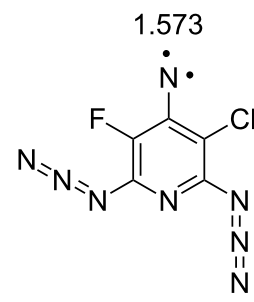

13-anti<smiles>N=N/N=N\c1nc(N=N)c(Cl)c(N=[W])c1F</smiles>

14-anti<smiles>[N-]=[N+]=Nc1nc(N=N)c(F)c(N=N)c1Cl</smiles>

14-syn

$$
D_{\top} \mathrm{SS}=1.053 \quad D_{\top} \mathrm{SS}=1.139
$$

$D_{\top}{ }^{S S}=1.135$

$D_{\top} S S=1.078$

$D_{\top}{ }^{S S}=1.126$

Figure 3: Mulliken spin populations on the nitrene units and parameters $D_{\top} \mathrm{SS}$ in $\mathrm{cm}^{-1}$ of triplet nitrenes $12-14$ at the PBE/DZ level of theory. 
the geometry optimizations of the most stable rotamers 11a and 11b in their lowest singlet excited states by using CIS/PM3 or CIS/6-311+G* calculations yield structures $11 \mathbf{a}-\mathrm{S}_{1} *$ and $11 \mathrm{~b}-\mathrm{S}_{1}$ *, in which the azido groups in ortho-positions to the fluorine atom are locally excited (Scheme 3 ). These calculations confirm that the local excitation of such groups requires lower activation energies [8,34]. According to theory [34-36], the local excitation of the azido group during the photoexcitation results in considerable bending of the $\mathrm{N}=\mathrm{N}=\mathrm{N}$ fragment from about $171^{\circ}$ to about $117^{\circ}$ and appearance of the $\sigma$-type antibonding interactions in the $\mathrm{N}-\mathrm{N}_{2}$ bond. Figure 4 illustrates these effects for the structure $11 \mathrm{a}-\mathrm{S}_{1}$ *

Thus, the first stage of the photolysis of triazide $\mathbf{1 1}$ in argon matrices involves the photochemical generation of excited states 11a- $\mathrm{S}_{1} *$ and $\mathbf{1 1 b}-\mathrm{S}_{1}$, which then undergo dissociation of the locally excited azido groups to form triplet nitrenes $\mathbf{1 2}$ and 13 (Scheme 3). On the second stage, triplet nitrenes 12 and 13 are excited to triplet states $12 \mathrm{a}-\mathrm{T}_{1} *, \mathbf{1 2 b}-\mathrm{T}_{1} *$ and $13 \mathbf{a}-\mathrm{T}_{1}$ * which then dissociate to quintet dinitrenes $\mathbf{1 5}$ and $\mathbf{1 6}$. The latter

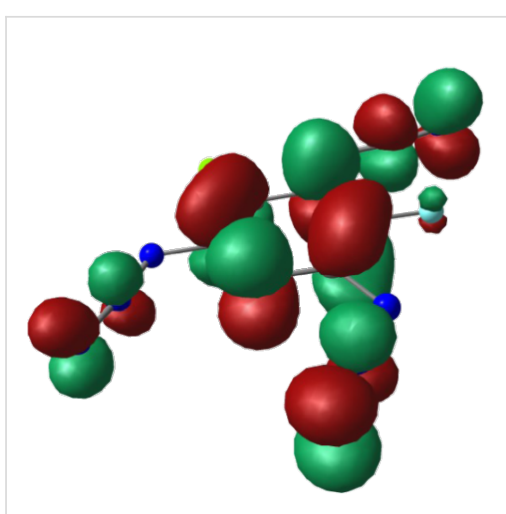

$11 a$

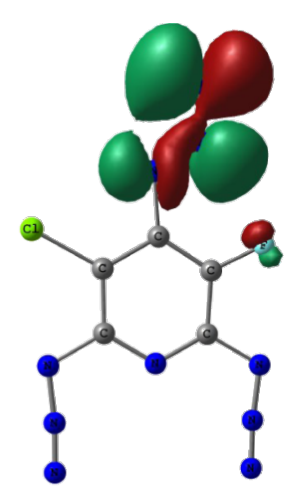

$11 \mathrm{a}-\mathrm{S}_{1}{ }^{*}$
Figure 4: UB3LYP/6-311+G* orbital density in the LUMO of triazide 11 and $C I S / 6-311+G^{*}$ orbital density in the highest singly occupied orbital of excited state $11 \mathrm{a}-\mathrm{S}_{1}{ }^{*}$.

is formed as the major product owing to efficient excitation of the azido groups located in ortho-positions to the fluorine atom of nitrenes $\mathbf{1 2}$ and $\mathbf{1 3}$. The photoexcitation of the azido group in<smiles>N=NN=Nc1c(F)c(N=N)nc(N=N)c1Cl</smiles><smiles>N=NN=Nc1nc(N=NN=N)c(Cl)c(N=NN=N)c1F</smiles><smiles>[N]c1nc(N=NN=N)c(Cl)c(N=N)c1F</smiles><smiles>N=Nc1nc(N)c(F)c(N=N)c1Cl</smiles>

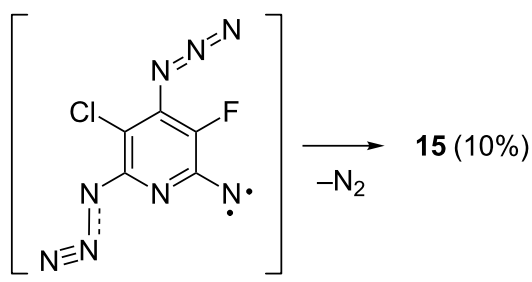

$12 \mathrm{~b}-\mathrm{T}_{1}$ * 
position $\mathbf{2}$ of nitrene $\mathbf{1 2}$ is a less efficient process leading to the formation of dinitrene $\mathbf{1 5}$ in just about $10 \%$ yield. The photoexcitation of the azido group in position $\mathbf{2}$ of nitrene $\mathbf{1 3}$ is a still much less efficient process. Quintet dinitrene $\mathbf{1 7}$ either is not formed at all or its yield is very low $(<6 \%)$. Finally, the photodecomposition of the remaining azido groups in dinitrenes $\mathbf{1 5}$ and $\mathbf{1 6}$ gives septet trinitrene $\mathbf{1 8}$ in just about $2 \%$ yield. The low yield of trinitrene $\mathbf{1 8}$ may be associated with low efficiency of the azido group excitation in quintet dinitrene $\mathbf{1 6}$ One also cannot exclude that the photoexcitation of quintet azidonitrenes into predissociation states is a much less efficient process in comparison with the photoexcitation of singlet azides. In contrast to singlet azides, quintet azidonitrenes already have four singly occupied orbitals, and photoexcitation of these species may lead to excited states in which the azido groups are not locally excited.

\section{Conclusion}

In contrast to theoretical expectations, photodissociation of triazide 11 with light at $\lambda=260-320 \mathrm{~nm}$ occurs selectively on the azido groups located in positions 4 and 6 of the pyridine ring to give triplet mononitrenes $\mathbf{1 2}$ and $\mathbf{1 3}$ as the primary photoproducts. On further irradiation, quintet dinitrenes 15 and $\mathbf{1 6}$ and septet trinitrene $\mathbf{1 8}$ are formed. The maximum yield of the latter is about just $2 \%$. Preferential photodissociation of the azido groups located in ortho-positions to the fluorine atom of pyridines is associated with strong $\pi$-conjugation of these groups with the pyridine ring. On photoexcitation, such azido groups are more efficiently involved in reorganization of the molecular electronic system and more easily adopt geometries of the locally excited predissociation states. Despite the lack of symmetry, trinitrene $\mathbf{1 8}$ shows a small parameter of $E_{S}=$ $-0.0034 \mathrm{~cm}^{-1}$ due to a large positive value of the spin-orbit coupling parameter $E_{S}$ SO $\left(\approx 0.005 \mathrm{~cm}^{-1}\right)$. In overall, the ZFS parameters of $\mathbf{1 8}$ are very close to the ZFS parameters of previously studied $C_{2 v}$ symmetric septet pyridyl-2,4,6-trinitrenes. The most accurate theoretical predictions of the ZFS parameters of $\mathbf{1 8}$ are obtained at the BLYP/EPRII level of theory. At the same time, modern DFT calculations are still too crude to be used for reliable EPR spectral identification of such structurally alike quintet isomers as dinitrenes 16 and 17. Such quintet isomers are better discriminated based on analysis of their dipolar angles $\Theta$. Among theoretical approaches, the most accurate estimations of the ZFS parameters of dinitrene $\mathbf{1 6}$ are obtained from $\mathrm{PBE} / \mathrm{DZ}$ calculations of its parameters $D_{S} \mathrm{SS}$ and $E_{S} \mathrm{SS}$. The study also demonstrates that successful EPR spectral simulations for nitrenes 15, 16 and $\mathbf{1 8}$ are possible only if additional line-broadening parameters $\Gamma(E)$ of $40-75 \mathrm{MHz}$ along with appropriate values of $g, S, D, E$ and $v_{0}$ are used in the spinHamiltonian calculations.

\section{Experimental}

Triazide 11 was synthesized according to the literature procedure [37]. X-band EPR spectra were recorded with a BrukerElexsys E500 EPR spectrometer with an ER077R magnet ( $75 \mathrm{~mm}$ gap between pole faces), an ER047 XG-T microwave bridge, and an ER4102ST resonator with a $\mathrm{TE}_{102}$ cavity. Solid argon matrices doped with triazide $\mathbf{1 1}$ were prepared by vacuum co-deposition of two separate molecular beams (Ar and triazide 11 vapor) on the tip of an oxygen-free high-conductivity copper rod (75 mm length, $3 \mathrm{~mm}$ diameter) cooled at $5 \mathrm{~K}$. The vapor of 11 was produced by an oven heating the polycrystalline $\mathbf{1 1}$ to $60{ }^{\circ} \mathrm{C}$. The matrix-isolated samples were irradiated with a highpressure mercury lamp, by using a filter passing the light at $\lambda=260-320 \mathrm{~nm}$, and spectra were recorded at various irradiation times.

The computer simulations of EPR spectra were performed by using the EasySpin program package (version 4.0.0) [38]. The simulations were performed by using matrix diagonalization methods for $S=1,2$ or 3 using the parameters $v_{0}=$ $9.605832 \mathrm{GHz}$ and $g=2.0023$ and line widths $\Delta H=60 \mathrm{G}$ for $S=1$, and $30 \mathrm{G}$ for $S=2$ and $S=3$.

The geometries of the molecules were optimized at the B3LYP/ 6-311G(d) level of theory with the Gaussian 03 program package [39]. The nature of the stationary points was assessed by means of vibrational frequency analysis. The spin-Hamiltonian parameters $(g, D, E)$ and orientations of the $\boldsymbol{D}$ tensor were obtained from additional single-point calculations with the ORCA program package [40,41]. DFT calculations of the direct spin-spin (SS) coupling $D^{\mathrm{SS}}$ and spin-orbit coupling (SO) $D^{\mathrm{SO}}$ parts of the $\boldsymbol{D}$ tensors were performed by using the McWeeny-Mizuno and Pederson-Khanna approaches, respectively [42].

\section{Supporting Information}

Supporting Information features EPR spectral simulations for quintet dinitrenes $\mathbf{1 5}-\mathbf{1 7}$ and septet trinitrene $\mathbf{1 8}$ as individual species and for the mixtures of quintet molecules with $E_{\mathrm{Q}} / D_{\mathrm{Q}}=0.039 / 0.209,0.038 / 0.213$ and $0.036 / 0.221$ at different molar ratios as well as EPR spectral simulations for nitrenes 15, 16 and $\mathbf{1 8}$ at different values of the line-broadening parameter $\Gamma(E)$.

\section{Supporting Information File 1}

EPR spectral simulations.

[http://www.beilstein-journals.org/bjoc/content/ supplementary/1860-5397-9-83-S1.pdf] 


\section{Acknowledgements}

This work was financially supported by the Deutsche Forschungsgemeinschaft, the Russian Foundation for Basic Research (grant RFBR 09-03-91330-DFG), the Russian Academy of Sciences (program OX-1) and the Fonds der Chemischen Industrie.

\section{References}

1. Bräse, S.; Banert, K., Eds. Organic Azides: Synthesis and Applications; Wiley-VCH: Chichester, U.K., 2010.

2. Scriven, F. F. V., Ed. Azides and Nitrenes, Reactivity and Utility; Academic Press: New York, USA, 1984.

3. Bräse, S.; Gil, C.; Knepper, K.; Zimmermann, V. Angew. Chem., Int. Ed. 2005, 44, 5188-5240. doi:10.1002/anie.200400657

4. Scriven, E. V. F.; Turnbull, K. Chem. Rev. 1988, 88, 297-368. doi:10.1021/cr00084a001

5. Chapyshev, S. V. Synlett 2009, 1-8. doi:10.1055/s-0028-1087479

6. Chapyshev, S. V. Russ. Chem. Bull. 2011, 60, 1274-1285. doi:10.1007/s11172-011-0195-7

7. Chapyshev, S. V.; Walton, R.; Sanborn, J. A.; Lahti, P. M. J. Am. Chem. Soc. 2000, 122, 1580-1588. doi:10.1021/ja993131c

8. Chapyshev, S. V.; Walton, R.; Lahti, P. M. Mendeleev Commun. 2000, 10, 187-188. doi:10.1070/MC2000v010n05ABEH001308

9. Finke, C.; Grote, D.; Seidel, R. W.; Chapyshev, S. V.; Sander, W. J. Phys. Org. Chem. 2012, 25, 486-492. doi:10.1002/poc.1943

10. Chapyshev, S. V.; Korchagin, D. V.; Budyka, M. F.; Gavrishova, T. N.; Neuhaus, P.; Sander, W. ChemPhysChem 2012, 13, 2721-2728. doi:10.1002/cphc.201200200

11. Nimura, S.; Yabe, A. In Magnetic Properties of Organic Materials; Lahti, P. M., Ed.; Marcel Dekker: New York, 1999; pp 127-145

12. Fukuzawa, T. A.; Sato, K.; Ichimura, A. S.; Kinoshita, T.; Takui, T.; Itoh, K.; Lahti, P. M. Mol. Cryst. Liq. Cryst. 1996, 278, 253-260. doi:10.1080/10587259608033683

13. Kalgutkar, R. S.; Lahti, P. M. J. Am. Chem. Soc. 1997, 119, 4771-4772. doi:10.1021/ja963723k

14. Chapyshev, S. V.; Walton, R.; Lahti, P. M. Mendeleev Commun. 2000, 10, 114-115. doi:10.1070/MC2000v010n03ABEH001281

15. Miura, Y.; Oka, H.; Teki, Y. Bull. Chem. Soc. Jpn. 2001, 74, 385-386. doi:10.1246/bcsj.74.385

16. Kalgutkar, R. S.; Lahti, P. M. Tetrahedron Lett. 2003, 44, 2625-2628. doi:10.1016/S0040-4039(03)00385-X

17. Chapyshev, S. V.; Tomioka, H. Bull. Chem. Soc. Jpn. 2003, 76, 2075-2089. doi:10.1246/bcsj.76.2075

18. Sato, T.; Narazaki, A.; Kawaguchi, Y.; Niino, H.; Bucher, G.; Grote, D.; Wolff, J. J.; Wenk, H. H.; Sander, W. J. Am. Chem. Soc. 2004, 126, 7846-7852. doi:10.1021/ja031794v

19. Chapyshev, S. V.; Walton, R.; Serwinski, P. R.; Lahti, P. M. J. Phys. Chem. A 2004, 108, 6643-6649. doi:10.1021/jp048764e

20. Chapyshev, S. V.; Lahti, P. M. J. Phys. Org. Chem. 2006, 19, 637-641. doi:10.1002/poc.1106

21. Chapyshev, S. V. Russ. Chem. Bull. 2006, 55, 1126-1131. doi:10.1007/s11172-006-0388-7

22. Chapyshev, S. V. Russ. Chem. Bull. 2006, 55, 1593-1597. doi:10.1007/s11172-006-0459-9

23. Misochko, E. Ya.; Akimov, A. V.; Chapyshev, S. V. J. Chem. Phys. 2008, 128, No. 124504. doi:10.1063/1.2840351
24. Koto, T.; Sato, K.; Shiomi, D.; Toyota, K.; Itoh, K.; Wasserman, E.; Takui, T. J. Phys. Chem. A 2009, 113, 9521-9526. doi:10.1021/jp9042717

25. Chapyshev, S. V.; Misochko, E. Ya.; Akimov, A. V.; Dorokhov, V. G.; Neuhaus, P.; Grote, D.; Sander, W. J. Org. Chem. 2009, 74, 7238-7244. doi:10.1021/jo9010848

26. Chapyshev, S. V. Russ. J. Phys. Chem. A 2009, 83, 254-259. doi:10.1134/S0036024409020186

27. Chapyshev, S. V.; Korchagin, D. V.; Budyka, M. F.; Gavrishova, T. N.; Neuhaus, P.; Sander, W. J. Phys. Chem. A 2011, 115, 8419-8425. doi:10.1021/jp203038k

28. Misochko, E. Ya.; Akimov, A. V.; Masitov, A. A.; Korchagin, D. V.; Yakushchenko, I. K.; Chapyshev, S. V. J. Chem. Phys. 2012, 137, No. 064308. doi:10.1063/1.4742342

29. Chapyshev, S. V.; Grote, D.; Finke, C.; Sander, W. J. Org. Chem. 2008, 73, 7045-7051. doi:10.1021/jo800425k

30. Misochko, E. Ya.; Akimov, A. V.; Chapyshev, S. V. J. Chem. Phys. 2008, 129, No. 174510. doi:10.1063/1.3005378

31. Chapyshev, S. V.; Neuhaus, P.; Grote, D.; Sander, W. J. Phys. Org. Chem. 2010, 23, 340-346. doi:10.1002/poc.1622

32. Misochko, E. Ya.; Korchagin, D. V.; Bozhenko, K. V.; Chapyshev, S. V.; Aldoshin, S. M. J. Chem. Phys. 2010, 133, No. 064101. doi:10.1063/1.3474574

33. Reiser, A.; Marley, R. Trans. Faraday Soc. 1968, 64, 1806-1815. doi:10.1039/TF9686401806

34. Korchagin, D. V.; Bozhenko, K. V.; Chapyshev, S. V.; Aldoshin, S. M High Energy Chem. 2009, 43, 289-293. doi:10.1134/S0018143909040080

35. Budyka, M. F.; Zyubina, T. S. J. Mol. Struct. 1997, 419, 191-199. doi:10.1016/S0166-1280(97)00244-3

36. Budyka, M. F. Russ. Chem. Rev. 2008, 77, 709-723. doi:10.1070/RC2008v077n08ABEH003793

37. Chapyshev, S. V. J. Fluorine Chem. 2011, 132, 991-994. doi:10.1016/j.jluchem.2011.07.012

38. Stoll, S.; Schweiger, A. J. Magn. Reson. 2006, 178, 42-55. doi:10.1016/j.jmr.2005.08.013

39. Gaussian 03, Revision D.01; Gaussian, Inc.: Wallingford, CT, 2004.

40. ORCA, an ab initio, density functional and semiempirical program package, Version 2.8.0.2; University of Bonn: Germany, 2011. The program was downloaded from http://cec.mpg.de/forum/

41. Neese, F. Wiley Interdiscip. Rev.: Comput. Mol. Sci. 2012, 2, 73-78. doi:10.1002/wcms.81

42. Neese, F. J. Chem. Phys. 2007, 127, No. 164112. doi:10.1063/1.2772857 


\section{License and Terms}

This is an Open Access article under the terms of the Creative Commons Attribution License

(http://creativecommons.org/licenses/by/2.0), which permits unrestricted use, distribution, and reproduction in any medium, provided the original work is properly cited.

The license is subject to the Beilstein Journal of Organic Chemistry terms and conditions:

(http://www.beilstein-journals.org/bjoc)

The definitive version of this article is the electronic one which can be found at:

doi:10.3762/bjoc. 9.83 